\title{
Identificación Multiatributo de Tipologías de Viviendas Vulnerables a Inundaciones en Riohacha, La Guajira-Colombia
}

\author{
Jhonny I. Pérez ${ }^{(1)}$, Andrea Nardini ${ }^{(2)}$ y Yesenia P. Zuñiga ${ }^{(1)}$ \\ (1) Grupo de Investigación GISA, Facultad de Ingeniería, Universidad de La Guajira, Km 5 Vía a Maicao, \\ Riohacha-Colombia. (e-mail: jpemon@uniguajira.edu.co; yesezunimen@gmail.com) \\ (2) Fundación CREACUA-Centro Recuperación Ecosistemas Acuáticos, calle 1ํㅗำ 1-109, Riohacha, La \\ Guajira-Colombia. (e-mail: nardiniok@gmail.com)
}

Recibido Dic. 29, 2017; Aceptado Mar. 7, 2018; Versión final May. 4, 2018, Publicado Oct. 2018

\section{Resumen}

Se han identificado las tipologías de viviendas más representativas en la ciudad de Riohacha en Colombia, para analizar el efecto de las inundaciones urbanas. Se aplicó la técnica de Análisis de Correspondencias Múltiples (ACM) en los datos previamente recolectados en una encuesta realizada a 411 viviendas de la zona afectada por inundaciones en la ola invernal 2010-2011. Se exploraron cuatro posibilidades entre la selección de los atributos a considerar y diferentes posibilidades de su medición en escalas cualitativas y cuantitativas. Se seleccionó el $A C M 3$ que agrupó las viviendas en 13 tipologías de las cuales se seleccionaron las cinco más representativas, incluyendo las viviendas más vulnerables (viviendas de un piso con paredes de bahareque). El ACM demostró ser una herramienta apta, suficientemente versátil y manejable, a pesar que requiere realizar un zoom al mapa perceptual cuando el análisis se hace con numerosos casos.

\section{Identification Multiattribute of Typologies of Flood-Vulnerable Housing in Riohacha, La Guajira- Colombia}

\begin{abstract}
The most representative house typologies in the city of Riohacha-Colombia have been identified with the aim of analyzing the effects of urban floods. The Multiple Correspondence Analysis (MCA) technique was applied to the data previously obtained through questionnaires to 411 households in the area affected by floods in the winter season 2010-2011. Four possibilities were explored between the selection of the attributes to be considered and different options for their measurement in qualitative and quantitative scales. The ACM3 which grouped the dwellings into 13 typologies was selected. From these, the five most representative ones were selected, including the most vulnerable dwellings (one-floor dwellings with wattle and daub walls). The ACM proved to be a suitable tool, because it is sufficiently versatile and manageable, although it requires a zoom to the perceptual map when the analysis is conducted with numerous cases.
\end{abstract}


Identificación Multiatributo de Tipologías de Viviendas Vulnerables a Inundaciones en Riohacha Pérez

\section{INTRODUCCIÓN}

Las inundaciones urbanas generan una preocupación cada vez más importante y un creciente problema social en todo el mundo (Vojinovic y Tutulic, 2009). El incremento de la urbanización y el aumento en la frecuencia e intensidad de lluvias extremas incrementa el riesgo local de inundaciones (Kundzewicz et al., 2013). Las inundaciones urbanas por lo general son más frecuentes en ciudades ubicadas en terrenos planos, especialmente donde los drenajes no están disponibles o son insuficiente, están mal construidos o han sido bloqueados por desechos municipales. El rápido crecimiento conduce a una urbanización mal planificada que hace que las poblaciones urbanas sean cada vez más vulnerables a las inundaciones. Los daños de las inundaciones urbanas son más intensos, costosos y difíciles de manejar que en zonas rurales (Sowmya et al., 2015). Los daños por inundación impactan directamente a los sectores sociales más pobres que son las principales víctimas del peligro de inundación. La pobreza juega uno de los roles más importantes porque induce una gran exposición, alta vulnerabilidad y baja capacidad de respuesta frente a las inundaciones; en efecto, un nivel significativo de ingresos es muy importante para enfrentar las pérdidas durante las inundaciones (Win et al., 2018). Factores tales como la geomorfología costera, los patrones de desarrollo urbano y las estructuras socioeconómicas afectan la forma en que un evento de riesgo costero daría lugar a pérdidas humanas, daños a la propiedad y trastornos económicos (IPCC, 2012).

Las inundaciones ocurridas en Colombia en el periodo 2010-2011 dejaron ver la necesidad de incluir nuevos conocimientos del clima y un enfoque diferente en la gestión del riesgo con procesos integrales y con mayor capacidad de adaptación de la sociedad colombiana en los próximos años (Sedano et al., 2012). La Niña del 2010-2011 es la mayor ola invernal de los últimos 50 años, y generó significativas pérdidas económicas y vidas humanas. Como discutido en Hoyos et al. (2013), esto impulsó la emanación de una política nacional de adaptación ante la alta vulnerabilidad del país frente al Cambio Climático (CC). Esta ola invernal generó un costo material superior a los $\$ 7$ billones de pesos colombianos y sólo el 5,1\% del valor de los bienes materiales perjudicados por inundaciones estaba asegurado (Palacio, 2011). Riohacha fue una de las ciudades colombianas más afectadas durante esta ola invernal sufriendo inundaciones y daños en varias zonas dejando miles de personas damnificadas por pérdida de bienes materiales, viviendas deterioradas y/o destruidas, y enfermedades (BID, 2012). En los últimos 10 años, las inundaciones en la ciudad de Riohacha son un fenómeno bastante frecuente, lo que hace muy difícil la vida para sus ciudadanos. De la ola invernal 2010-2011, el evento más fuerte de inundación ocurrió el 18 de septiembre de 2011.

Entre las principales causas que favorecieron la ocurrencia de inundaciones en Riohacha en el periodo 20102011 según las fuentes oficiales (Municipio de Riohacha, 2012) están: el mal diseño y carencia de la infraestructura del alcantarillado pluvial, descuido y falta de mantenimiento que lleva al frecuente taponamiento en los desagües naturales, alcantarillas y pluviales, la poca acción por parte de las autoridades competentes ante el problema de saneamiento, la mala infraestructura del $80 \%$ aproximadamente de las viviendas, la mala pavimentación de algunas vías principales. De acuerdo al estudio realizado por Nardini y Miguez (2016), si bien los factores antes mencionados concurren a generar el problema, quizás las causas principales resultan ser más bien: la edificación en zonas de almacenamiento o desagüe natural, múltiples interrupciones del eje de drenaje natural (según la topografía y morfología del territorio) y su conexión con el rio Ranchería, el mal manejo de los humedales presentes en el territorio, y la impermeabilización generalizada de buena parte de la cuenca urbana.

En busca de alternativas de solución a las inundaciones, se desarrolló el proyecto denominado: Adaptación urbana "verde" frente a inundaciones con el soporte de la modelación matemática MODCEL en Riohacha, La Guajira-Colombia, en adelante "Proyecto MODCEL", promovido y coordinado por la fundación Centro de Recuperación de Ecosistemas Acuáticos (CREACUA), financiado por la Unidad Nacional de Gestión de Riesgos y Desastres (UNGRD) de Colombia, co-financiado por la Alcaldía Municipal de Riohacha, y desarrollado con la fuerte colaboración de la Universidad Federal de Río de Janeiro - UFRJ y de la Universidad de La Guajira -UNIGUAJIRA (CREACUA, 2015). Este proyecto, basado en la modelación de la amenaza, llegó a redactar un plan integrado anti inundaciones a través de un enfoque multicriterio utilizando para evaluar el riesgo indicadores proxy como el número de viviendas afectadas por distintos tiempos de retorno; pero no evaluó el riesgo en sentido de valor esperado de los daños asociados a las inundaciones.

Para seguir mejorando y llegar a utilizar estimaciones del riesgo por inundación, además de estimar la amenaza y el valor de los bienes afectados, se necesitan curvas de daños, como recomienda, dentro de sus múltiples alcances, el proyecto CAPRA (Banco Mundial, 2016). Estas curvas se utilizan para evaluar los daños tangibles directos; ellas describen la relación entre la profundidad de la inundación y la fracción del valor del inmueble y bienes perdidos. Para construir de manera directa (enfoque ingenieril), para construir estas curvas de daños es necesario definir las características de las construcciones (Baró-Suárez et al., 2007; Nascimento et al., 2007; Velasco et al, 2015; Win et al., 2018). Es por ello, que el grupo de trabajo persiguió el propósito de identificar tipologías de viviendas representativas en el área de interés. 
La clasificación tipológica como disciplina y método científico representa una herramienta sólida que puede permitir la sistematización del conocimiento que existe, obtener más fácilmente la información y conectar el conocimiento más viejo con el recién. Las tipologías se usan en varios campos de la investigación (Vujicic, 2011) y han sido un apoyo desde 1735 empleándose ampliamente para identificar oportunidades de planificación y políticas en la industria, el comercio electrónico, la arquitectura, la agricultura, el desarrollo urbano, la gestión de los ríos, la silvicultura y la infraestructura verde (Young et al., 2014).

En la planificación urbana, es necesario determinar tipologías incluyendo condiciones físicas, económicas y sociales; dentro de estos aspectos las viviendas son factor clave (Budiyantini y Pratiwi, 2016). Las tipologías permiten generar rápidamente visualizaciones y evaluaciones para una variedad de escenarios de viviendas para luego determinar por parte de los planificadores y formuladores de políticas urbanísticas soluciones aptas (Trubka y Glackin, 2016). Determinar el tipo de viviendas (históricas, residenciales, suburbanas, industriales) se ha convertido en tendencia en una amplia gama de estudios y aplicaciones (Hermosilla et al., 2014) e incluso para definir tipologías de infraestructura verde urbana, que incluya factores sociales y ecológicos más complejos (Young et al., 2014); el caso de Young et al. (2014) es similar al Proyecto MODCEL, pero en este ultimo la definición de tipologías tiene el propósito de la evaluación de los daños ocurridos por las inundaciones del periodo 2010-2011 y del riesgo para fines de planeación futura.

Las tipologías se han usado para justificar la conservación de viviendas típicas como patrimonio arquitectónico (Mahayuddin et al., 2017). Distinguir tipologías de viviendas puede ayudar a los ingenieros estructurales, arquitectos y planificadores urbanos a comprender el comportamiento y la respuesta ante cualquier tipo de riesgo natural o antrópico. Por lo tanto, una clasificación tipológica es un requisito previo fundamental para cualquier estudio de evaluación de vulnerabilidad o pérdida (Lang et al., 2018). Aunque ya estudiada en muchos países o regiones, las tipologías de viviendas deben ser determinadas con la peculiaridad regional (Merz et al., 2010). En este sentido, en igualdad de calado, los daños pueden ser radicalmente diferentes para cada tipo de estructura (Luino et al., 2009). Sin embargo, construir una curva para cada tipología de vivienda presente en el territorio considerado sería un esfuerzo desproporcionado con respecto al resultado obtenible. Por ello, en este trabajo se buscó identificar un número mínimo de tipologías representativas de las viviendas presentes en el área de estudio.

El uso de materiales locales, la armonización con el entorno y el clima local es uno de los aspectos muy apreciados en una tipología de viviendas tradicionales (Mahayuddin et al., 2017). En Riohacha es tradición de los indígenas Wayuu la vivienda de bahareque (barro con alma de madera), pero es una vivienda muy vulnerable a las inundaciones y muchas veces construida en zonas de alto riesgo, lo que abre el camino a su probable destrucción. En el marco de los proyectos internacionales TABULA y EPISCOPE (http://episcope.eu/index.php?id=97), se han creado tipologías de edificios residenciales en 20 países europeos. Cada tipología nacional agrupa las construcciones según su tamaño, edad y otros parámetros que permiten agruparlas por características comunes y estudiar sus ventajas y desventajas (Loga et al., 2016).

Para identificar las tipologías de las viviendas en Riohacha, se utilizó el Análisis de Correspondencias Múltiples (ACM). El ACM permite visualizar e interpretar grandes conjuntos de datos, y de aplicación en casi todas las ramas de la investigación científica. El ACM es un método descriptivo multivariante donde las observaciones se describen por variables categóricas o una tabla de contingencia de múltiples vías (Fithian y Josse, 2017). El ACM es uno de los métodos de reducción de dimensionalidad más popular que permite tener en cuenta la co-linealidad de las variables, evitando así la información redundante. Con el ACM se obtienen categorías homogéneas en su composición y heterogéneas entre ellas (Padilla et al., 2016). El ACM es particularmente apto en la búsqueda de tipologías respecto a variables cualitativas categórica; puede ser aplicado inclusive para variables continuas, siempre que se transformen en categóricas (Rodrigues et al., 2016).

El objetivo del presente trabajo fue identificar las tipologías de viviendas más representativas de la ciudad de Riohacha, en términos de cantidad y vulnerabilidad, es decir no se llega a evaluar los daños generados por la inundación. La vulnerabilidad es un aspecto muy importante para planificar la prevención o mitigación del riesgo por inundación, necesidad que tienen los tomadores de decisiones. La base de partida fue la encuesta generada por el proyecto MODCEL con información socioeconómica, características de la vivienda y daños ocurridos en la ciudad de Riohacha durante la pasada ola invernal 2010-2011.

\section{METODOLOGÍA}

Para el desarrollo del presente estudio se delimitó el área de interés dentro de la zona urbana de la ciudad de Riohacha, La Guajira-Colombia, el criterio fue considerar las zonas más afectada por la ola invernal 20102011. Para determinar las tipologías se adoptó un enfoque multiatributo. 


\section{Área de estudio}

El estudio se llevó a cabo en la ciudad de Riohacha, La Guajira-Colombia, ciudad costera con una población estimada al año 2013 (año en el que se aplicó la encuesta) de 240.951 habitantes aproximadamente, donde el $81,28 \%$ viven en la zona urbana. El clima de la ciudad es considerado BSh (semiárido cálido) según la clasificación climática de Köppen-Geiger. La temperatura media anual es $28,3{ }^{\circ} \mathrm{C}$ y la precipitación media aproximada es de $588 \mathrm{~mm}$, siendo octubre el mes más lluvioso con 18 días de lluvia aproximadamente (https://es.climate-data.org/location/714990/). Por lo general, en los meses lluviosos se registran aguaceros de alta intensidad y poca duración. Dentro del área urbana de la ciudad de Riohacha se encuentran 4 humedales: Jagüey Boca Grande, Jagüey La Esperanza, Jagüey 31 de Octubre y Laguna Salá, los dos últimos de origen natural, sus aguas drenan hacia el delta del río Ranchería, concretamente el brazo El Riíto brazo principal de este río. Estos humedales ejercen una marcada importancia en el tema de las inundaciones con un área de influencia bastante extensa denominada en el proyecto MODCEL como "cuenca urbana", la cual es nuestra zona área de estudio.

En la Figura 1 se ilustra la ubicación de la ciudad de Riohacha y la zona de estudio en el contexto de Colombia. Cabe notar que, a diferencia de una cuenca hidrológica, la cuenca urbana es más difícil de definir porque dependiendo de los niveles de inundación alcanzados una zona puede llegar a interactuar con otra, previamente considerada como externa, inclusive por causa de elementos artificiales, como canales pluviales; por tanto, la delimitación no se hace puramente con un criterio topográfico-morfológico, sino que implica también características infraestructurales e hidráulicas. Este hecho indica que su definición es típicamente resultado de un proceso iterativo y no tiene validez absoluta.

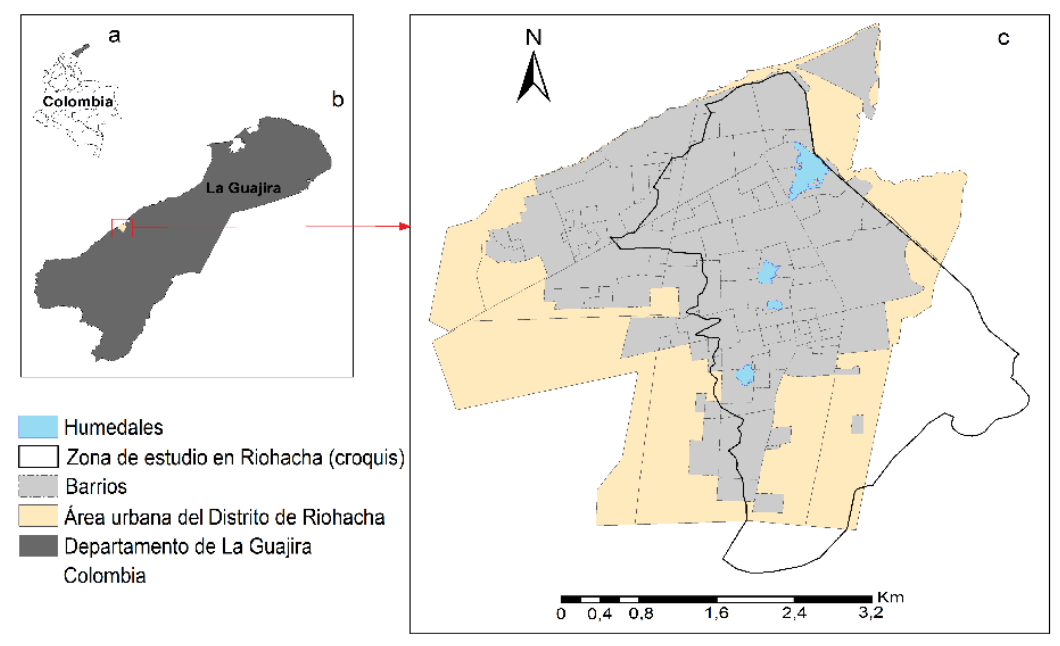

Fig.1: Localización geográfica del área de estudio. La Guajira en Colombia (a), Riohacha en el departamento de La Guajira (b), cuenca urbana y humedales en Riohacha (c).

\section{Condiciones socioeconómicas del área de estudio}

Para ilustrar las condiciones socioeconómicas de la ciudad de Riohacha, se presentan en la Tabla 1 las condiciones de pobreza, pobreza extrema y desigualdad (coeficiente de Gini), lo que posiciona a Riohacha en el penúltimo lugar a nivel nacional. En Colombia se considera pobre a un hogar que recibe (en el año 2017) el monto de $\$ 250.620$ mensuales es decir un 33,97\% del salario mínimo legal vigente que para el 2017 fue de $\$$ 737.717. La pobreza extrema ocurre cuando el ingreso mensual per cápita de un hogar se sitúa por debajo de la línea de indigencia monetaria (\$116.330 para el año 2017). El coeficiente o índice general de Gini es la medida más popular entre economistas y sociólogos para expresar la desigualdad de una sociedad (Chatterjee et al., 2017). Para el año 2017, la pobreza a nivel nacional fue de 26,9\%, pobreza extrema de $7,4 \%$ y coeficiente de Gini de 0,508 (DANE, 2018); se puede afirmar que existen grandes diferencias entre Riohacha y el promedio del país.

De acuerdo a los datos de la Tabla 1, Riohacha presentó un retroceso de 7 años, ya que los indicadores del 2017 son similares a los del año 2010. Es importante aclarar que una disminución en el Gini puede no ser necesariamente una mejora para el grupo más pobre. Para el mes de septiembre de 2015 el Municipio de Riohacha fue declarado Distrito Turístico y Cultural, con la esperanza de abrir nuevos caminos al desarrollo social y económico, sin embargo, finalizado el 2017, aún no se observan cambios favorables; por el contrario, los indicadores socioeconómicos desmejoraron. 
Tabla 1: Indicadores socioeconómicos de Riohacha en el periodo 2010-2017. Fuente: DANE, 2018

\begin{tabular}{|c|c|c|c|}
\hline Año & Pobreza & $\begin{array}{c}\text { Pobreza } \\
\text { extrema }\end{array}$ & $\begin{array}{c}\text { Coeficiente } \\
\text { de Gini }\end{array}$ \\
\hline 2010 & 46,9 & 14,2 & 0,523 \\
\hline 2011 & 42,7 & 9,3 & 0,504 \\
\hline 2012 & 45,5 & 14,4 & 0,529 \\
\hline 2013 & 43,3 & 12,7 & 0,523 \\
\hline 2014 & 42,4 & 12,4 & 0,517 \\
\hline 2015 & 41,0 & 12,7 & 0,522 \\
\hline 2016 & 45,5 & 15,3 & 0,520 \\
\hline 2017 & 46,9 & 15,1 & 0,524 \\
\hline
\end{tabular}

Las características socioeconómicas de una población influyen en todos los aspectos de un individuo, dentro de ellos el tipo de construcciones, cuya vulnerabilidad frente a cualquier evento se incrementa con el nivel de pobreza del grupo familiar. Por tal razón estos aspectos fueron incluidos en la encuesta realizada en la zona de estudio tal como se explica en el apartado "Enfoque multiatributo".

\section{Estado de las viviendas al momento de aplicar la encuesta}

La encuesta fue aplicada en los meses de octubre a noviembre del 2013, esto es dos años después de la inundación de interés. Al momento de hacer estudios profundos tiempo después de haber ocurrido la problemática nos enfrentamos que las condiciones han podido cambiar u olvidar detalles al encuestado (Nardini y Miguez, 2016). Sin embargo, la aplicación de encuestas años después de ocurrido un evento de inundación es común. En la ciudad de Itajuba, Brasil se aplicó una encuesta en el año 2002 para recolectar información de lo ocurrido en una fuerte inundación que había sufrido la ciudad en el año 2000 (Nascimento et al., 2007). En Bélgica se desarrolló una encuesta en el año 2013 para conocer el efecto de la inundación más grave a partir del año 2000 (Van Ootegem et al., 2015). En la cuenca del río Bago, Myanmar, se realizó una encuesta inicial en junio de 2016 y la segunda en mayo de 2017 para entender lo ocurrido en las inundaciones del año 2011 en zona residencial y agrícola (Win et al., 2018). Es intuitivo que cuanto más impactante fue el evento, cuanto más confiable será el dato tomado a distancia de años del mismo; el evento ola invernal fue para Riohacha (como para muchas otras ciudades en Colombia) memorable.

La prevalencia o cambio de una determinada tipología de construcción depende de varios factores entre los que se pueden mencionar: Apoyo de las autoridades estatales, nivel socioeconómico, conocimiento autóctono sobre tipologías de construcción tradicionales, conocimiento de los artesanos y albañiles, estado de desarrollo de la región, disponibilidad de materiales de construcción, clima y condiciones climáticas, historial de los peligros (Lang et al., 2018). Los factores y circunstancias antes expuestas permitieron que las tipologías de viviendas entre la fecha de las inundaciones y la aplicación de las encuestas en Riohacha no hubiesen cambiado. Se pueden determinar tipologías para muchos fines, por tanto, no dependen del daño o riesgo que pueden o hayan sufrido. En el trabajo de campo fue observado que en algunos casos los propietarios arreglaron sus viviendas con recursos propios, pero la mayoría solo realizó labores de limpieza, por lo que fueron habitadas sin arreglar, sobre todo cuando quien vive en la vivienda no es el propietario. Por otro lado, el Estado colombiano entregó, en septiembre de 2016, 150 viviendas a los más afectados de la ola invernal del 2010-2011 residentes en el área urbana de la ciudad de Riohacha; estas viviendas fueron construidas en torres de 5 pisos fuera del área de estudio. Una gran debilidad de estos programas es no hacer la demolición de las viviendas compensadas y posesión del predio por parte del ente territorial, por tal razón actualmente siguen ocupadas por los mismos residentes o familiares (o nuevos sub-arrendatarios), convirtiéndose en nuevas víctimas de las inundaciones. Otro aspecto que agrava el problema es la fuerte debilidad para planificar el territorio que ha imperado y aún existe en la ciudad de Riohacha, haciendo que sus habitantes hagan sus construcciones en zonas de alto riesgo sin considerar criterios de adaptación.

\section{Enfoque multiatributo}

Se realizó una encuesta con el fin de conocer los daños, los aspectos socioeconómicos, niveles históricos de inundación y determinar los tipos de viviendas. En la Figura 2 se puede apreciar a nivel general el esquema metodológico usado en el proyecto MODCEL, en este artículo se usan los datos pertinentes de la encuesta para determinar las tipologías de viviendas. Al momento del estudio se encontraban 14.352 viviendas en la zona de interés. Dado que se conocía el tamaño de la población (N), se definió un nivel de confianza del 95\% 
$(Z=1,96)$, un error máximo admisible en término de proporción del $5 \%$. No se tenía seguridad de la probabilidad de éxito $(p)$, es decir si la vivienda había sido inundada, por tanto, para garantizar el mayor tamaño de muestra $(n)$, se consideró $p=0,5$. Con estas consideraciones y de acuerdo a Valdivieso et al. (2011), se obtiene un tamaño de muestra de $n=374$ viviendas; por seguridad se decidió realizar 411 encuestas distribuidas proporcionalmente de acuerdo a la población del barrio o comuna.

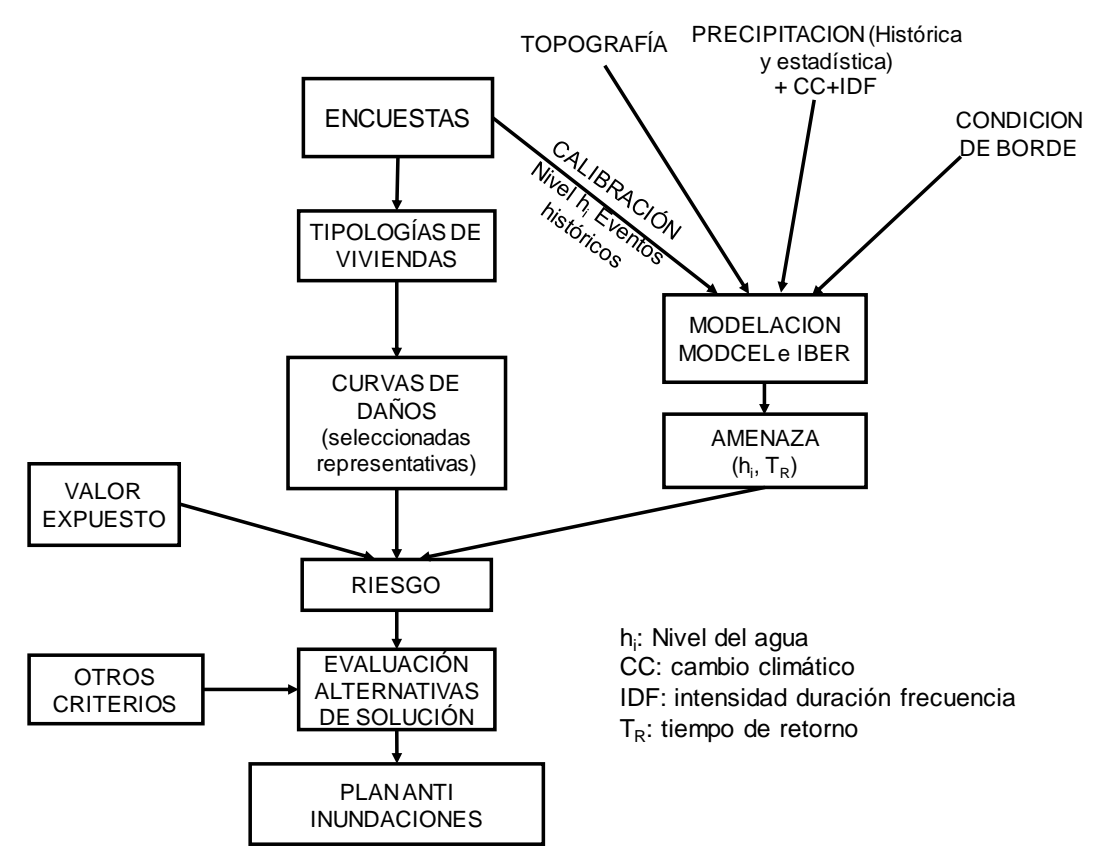

Fig. 2: Esquema metodológico.

En Colombia existe mucha heterogeneidad en las viviendas y aunque similares en algunas regiones, nos pareció necesario identificarlas en relación al contexto especifico de Riohacha por sus peculiaridades, tal como lo recomienda Merz et al. (2010). Por tanto, en la encuesta realizada en Riohacha se adoptó un enfoque multiatributo para caracterizar las viviendas encuestadas, incluyendo 22 atributos socioeconómicos (composición del núcleo familiar, nivel y tipo de educación e ingresos, etc.), físico-constructivos (número de pisos, material de los muros externos, numero de cuartos, tamaño, etc.), físico-hidráulicos (desnivel entre piso más bajo y cota de la calle al frente, altura de la eventual barrera anti-inundaciones en la entrada), económico (bienes presentes como colchones, televisores, víveres entre otros) y una serie de indicadores relacionados con los daños sufridos en cada evento de inundación (valor de los daños directos sufridos, gastos efectivamente sostenidos para reparar los daños sufridos, número de días de escuela perdidos por enfermedades o imposibilidad de movilización, días laborales perdidos, entre otros). El contenido de la encuesta realizada en Riohacha es muy similar al recomendado por Suriya et al. (2012), es decir contiene información general, detalles demográficos, socioeconómicos al igual que se ha aplicado en otras investigaciones para cuantificar daños por inundación (Nascimento et al., 2007; Van Ootegem et al., 2015; Win et al., 2018). La encuesta aplicada en Riohacha considera muchos aspectos y busca como fin último evaluar los daños, sin embargo, el uso en este artículo es para definir las tipologías de viviendas.

Se realizó una identificación de las tipologías más representativas de los valores asumidos por estos atributos utilizando la técnica del Análisis de Correspondencias Múltiples (ACM); técnica seleccionada por su aptitud para los casos en que algunos o todos los atributos se expresan con indicadores de tipo categórico como es el caso de las encuestas (Fithian y Josse, 2017). Los ejes (dimensiones) de los mapas perceptuales obtenidos en el ACM permite conocer la relación entre las categorías de una misma variable y entre categorías de distintas variables (Esmaelian et al., 2017). Los puntos representan objetos y categorías de las variables que en nuestro caso corresponden a las viviendas. Para organizar y sistematizar las encuestas se utilizó el software Microsoft Office Access 2013 y los ACM fueron realizados en el software estadístico SPSS (Licencia Universidad de La Guajira). Antes de llegar a los resultados fue necesario explorar varias opciones alternativas técnicamente relevantes para este tipo de análisis. Por un lado, se tuvo que decidir cómo tratar los atributos medidos por indicadores cuantitativos (escalas continuas, de razones, como tamaño de la vivienda o desniveles) o cualitativos preferenciales (escalas discretas ordinales, como es el caso por ejemplo de: "pequeña, mediana, grande y muy grande" para el caso del tamaño de las viviendas; "nada, poco, normal, mucho, muchísimo" como en el caso de los bienes), con respecto a los demás de tipo categórico (escalas discretas, no ordinales es decir nominal), como: "tipo de piso" (que puede ser tierra/arena, cemento, baldosa/vinilo); se trataba entonces de discretizar creando para cada clase un nuevo atributo nominal con 
valores posibles: "positivo, negativo o nulo", para el caso por ejemplo de los desniveles. Por otro lado, se exploraron diversos conjuntos de atributos a considerar porque no necesariamente el conjunto máximo era más informante, dado que el incremento de información puede (y de hecho era) ser obscurecido por un superior incremento de "ruido" de información (incoherencias, errores). Finalmente, se tuvo que decidir cuántas tipologías diversas aceptar, explorando entre un mínimo de 4 y un máximo de 20 (extremos envolventes de resultados de las distintas pruebas con distintas opciones).

Finalmente, se adoptaron los siguientes criterios para llegar a un análisis significativo seleccionando el ejercicio ACM que mejor los cumpla: i) que tenga el menor número de tipologías posibles, ii) mayor número de viviendas capturadas por las tipologías generadas y iii) logre capturar las viviendas con características más vulnerables (viviendas tradicionales con pared de bahareque, o sea de barro con alma en madera). Para ello, se realizaron diversos intentos tal como se muestra en la Tabla 2. El ACM1 se realizó con 411 viviendas y desniveles sin categorizar (valor cuantitativo), para el ACM2 se descartaron 5 viviendas por datos faltantes y todas sus variables fueron cualitativas. El ACM3 se realizó igual que el ACM2, excluyendo los desniveles y para el ACM4 las mismas consideraciones que el ACM3 adicionando los bienes, en los cuales se encontraron 95 casos con datos faltantes, es decir se realizó con 316 viviendas.

Tabla 2: Variables utilizadas y su categorización

\begin{tabular}{|c|c|c|c|c|}
\hline \multicolumn{2}{|r|}{ Variables } & $\begin{array}{l}\text { Respuestas posibles previstas } \\
\text { en la encuesta }\end{array}$ & Categorización de las variables & $A C M$ \\
\hline \multirow{8}{*}{ 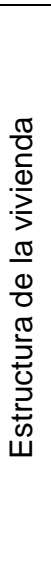 } & \multirow{4}{*}{$\begin{array}{l}\text { Tamaño de la } \\
\text { vivienda }\end{array}$} & $\leq 80 \mathrm{~m}^{2}$ & Pequeña & \multirow{4}{*}{$\begin{array}{c}\text { ACM1, ACM2, ACM3 y } \\
\text { ACM4 }\end{array}$} \\
\hline & & $(81-120) \mathrm{m}^{2}$ & Mediana & \\
\hline & & $(121-200) \mathrm{m}^{2}$ & Grande & \\
\hline & & $\geq 201 \mathrm{~m}^{2}$ & Muy grande & \\
\hline & Tipo de piso & $\begin{array}{l}\text { Tierra, cemento, baldosa/vinilo, } \\
\text { tableta ladrillo }\end{array}$ & $\begin{array}{l}\text { Tierra, cemento, baldosa/vinilo, } \\
\text { tableta ladrillo }\end{array}$ & $\begin{array}{c}\text { ACM1, ACM2, ACM3 y } \\
\text { ACM4 }\end{array}$ \\
\hline & Tipo de pared & $\begin{array}{l}\text { Bahareque o barro, bloque, } \\
\text { cemento, ladrillo, lata o platico, } \\
\text { madera burda }\end{array}$ & $\begin{array}{l}\text { Bahareque o barro, bloque, } \\
\text { cemento, ladrillo, lata o platico, } \\
\text { madera burda }\end{array}$ & $\begin{array}{c}\text { ACM1, ACM2, ACM3 y } \\
\text { ACM4 }\end{array}$ \\
\hline & Tipo de estructura & $\begin{array}{l}1 \text { piso con patio, } 1 \text { piso sin } \\
\text { patio, } 2 \text { pisos con patio y } 2 \\
\text { pisos sin patio }\end{array}$ & $\begin{array}{l}1 \text { piso con patio, } 1 \text { piso sin } \\
\text { patio, } 2 \text { pisos con patio y } 2 \\
\text { pisos sin patio o }\end{array}$ & $\begin{array}{c}\text { ACM1, ACM2, ACM3 y } \\
\text { ACM4 }\end{array}$ \\
\hline & Desniveles & $\begin{array}{c}\text { Interno y externo (expresada } \\
\text { en números) }\end{array}$ & $\begin{array}{l}\text { Cuantitativa (ACM1) y } \\
\text { negativos, positivos, valores } \\
\text { ceros (ACM2) }\end{array}$ & ACM1, ACM2 \\
\hline \multirow{30}{*}{ 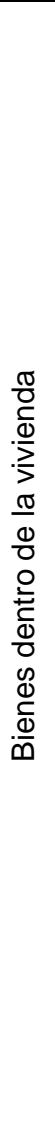 } & \multirow{5}{*}{$\begin{array}{l}\text { Número de } \\
\text { colchones }\end{array}$} & 0 & nada & \multirow{30}{*}{ ACM4 } \\
\hline & & $1-3$ & poco & \\
\hline & & $3-7$ & normal & \\
\hline & & $8-10$ & mucho & \\
\hline & & $>10$ & muchísimo & \\
\hline & \multirow{5}{*}{$\begin{array}{l}\text { Número de } \\
\text { televisores }\end{array}$} & 0 & Nada & \\
\hline & & 1 & poco & \\
\hline & & $2-3$ & normal & \\
\hline & & $4-5$ & mucho & \\
\hline & & $>5$ & muchísimo & \\
\hline & \multirow{5}{*}{$\begin{array}{l}\text { Número de } \\
\text { electrodomésticos }\end{array}$} & 0 & Nada & \\
\hline & & $1-5$ & poco & \\
\hline & & $6-11$ & normal & \\
\hline & & $12-17$ & mucho & \\
\hline & & $>17$ & muchísimo & \\
\hline & \multirow{5}{*}{$\begin{array}{l}\text { Numero de libros } \\
\quad+C D\end{array}$} & 0 & Nada & \\
\hline & & $1-200$ & poco & \\
\hline & & $200-500$ & normal & \\
\hline & & $501-1000$ & mucho & \\
\hline & & $>1000$ & muchísimo & \\
\hline & \multirow{5}{*}{$\begin{array}{l}\text { Número de } \\
\text { lencerías }\end{array}$} & 0 & Nada & \\
\hline & & $1-200$ & poco & \\
\hline & & $200-600$ & normal & \\
\hline & & $601-1000$ & mucho & \\
\hline & & $>1000$ & muchísimo & \\
\hline & \multirow{5}{*}{$\begin{array}{l}\text { Kilogramos de } \\
\text { víveres }\end{array}$} & 0 & Nada & \\
\hline & & $1-300$ & poco & \\
\hline & & $301-700$ & normal & \\
\hline & & $701-1500$ & mucho & \\
\hline & & $>1500$ & muchísimo & \\
\hline
\end{tabular}


Las viviendas de cada tipología fueron ubicadas en un mapa de inundación obtenido a través de modelación hidráulica realizada con IBER versión 2.3.1 descrito en Pérez et al. (2016), lo que permitió apreciar cuantas caían en la zona de amenaza, además sirvió de base para decidir sobre las tipologías a las cuales realizar las curvas de daños. Para la cartografía se usó el software ArcGIS (licencia Universidad de La Guajira).

\section{RESULTADOS Y DISCUSIÓN}

En la Tabla 3 se presentan los indicadores y variables influyentes obtenidos en cada ACM. En todos los casos la varianza explicada total superó el $50 \%$, lo que indica que el mapa perceptual con dos dimensiones es adecuado (Esmaelian et al., 2017). La varianza fue mayor en la dimensión 1, esto quiere decir que los valores asumidos por los atributos (categorías) presentan mayor dispersión de varianza en esta dimensión. El ACM3 tiene la más alta explicación de la variabilidad de los datos con un total de $91,85 \%$; un $52,41 \%(48,14 / 91,85)$ explicada por la primera dimensión (D1) y 47,58\% $(43,71 / 91,85)$ explicada por la segunda dimensión (D2). En el ACM1, ACM2 y ACM3 el tipo de pared es una variable clave global, es decir comparte características con variables de ambas dimensiones, esta variable, sin ser la única, es muy importante para definir el tipo de vivienda y con ello la vulnerabilidad. En el ACM1 y ACM2 se utiliza la variable desnivel (interno y externo), sin categorizar y categorizado respectivamente; se nota que éste no influyó de forma importante en ninguna dimensión, es decir, no comparte características con las otras variables y por tanto aporta muy poca información para definir el tipo de vivienda, razón por la cual fue excluido del ACM3 y ACM4. En el ACM4 las variables están más relacionadas con la dimensión 1 (medida de discriminación superior a 0,99), contrario a la dimensión 2 donde no existen variables dominantes (discriminación entre 0,344 a 0,382).

Tabla 3: Resultados de los análisis de correspondencias múltiples.

\begin{tabular}{|l|c|c|c|c|l|l|}
\hline \multirow{2}{*}{ ACM } & \multicolumn{2}{|c|}{$\begin{array}{c}\text { Alfa de } \\
\text { Cronbach }\end{array}$} & \multicolumn{2}{c|}{$\begin{array}{c}\text { Inercia o } \\
\text { varianza } \\
\text { explicada (\%) }\end{array}$} & \multicolumn{2}{|c|}{ Variables influyentes } \\
\cline { 2 - 7 } & $D 1$ & $D 2$ & $D 1$ & $D 2$ & $D 1$ & \multicolumn{1}{c|}{$D 2$} \\
\hline ACM1 & 0,616 & 0,581 & 34,26 & 32,32 & Tamaño, Tipo de piso y pared & Estructura y pared \\
\hline ACM2 & 0,588 & 0,552 & 32,68 & 30,85 & Tamaño, Tipo de piso y pared & Estructura y pared \\
\hline ACM3 & 0,641 & 0,571 & 48,14 & 43,71 & Tamaño, Tipo de piso y pared & Estructura y pared \\
\hline ACM4 & 0,842 & 0,730 & 41,36 & 29,13 & $\begin{array}{l}\text { Estructura, cantidad de colchones, } \\
\text { televisores y electrodomésticos }\end{array}$ & $\begin{array}{l}\text { Tamaño, paredes, piso y } \\
\text { lencería }\end{array}$ \\
\hline
\end{tabular}

El alfa de Cronbach es un indicador de la fiabilidad de la escala de medida, indica también qué tan correlacionadas están las variables observables que componen cada dimensión. El ACM4 tiene mayor alfa de Cronbach que el ACM3 quien tiene la mayor varianza explicada, lo que a simple vista no es muy lógico dado que tiene una relación directa con la inercia. Lo anterior se debe a que el ACM4 no se realizó con el mismo número de casos que el ACM3. En el ACM4 las variables más influyentes son los bienes y no las relacionadas con la infraestructura. Sin embargo, la varianza explicada del ACM3 da muestra suficiente que los contenidos internos en las viviendas influyen muy poco en sus características, mientras se pensaba lo contario al inicio de esta investigación. De forma gráfica se muestra en la Figura 3 el mapa "perceptual" de los ACM3 (Figura 3a) y ACM4 (Figura 3b).
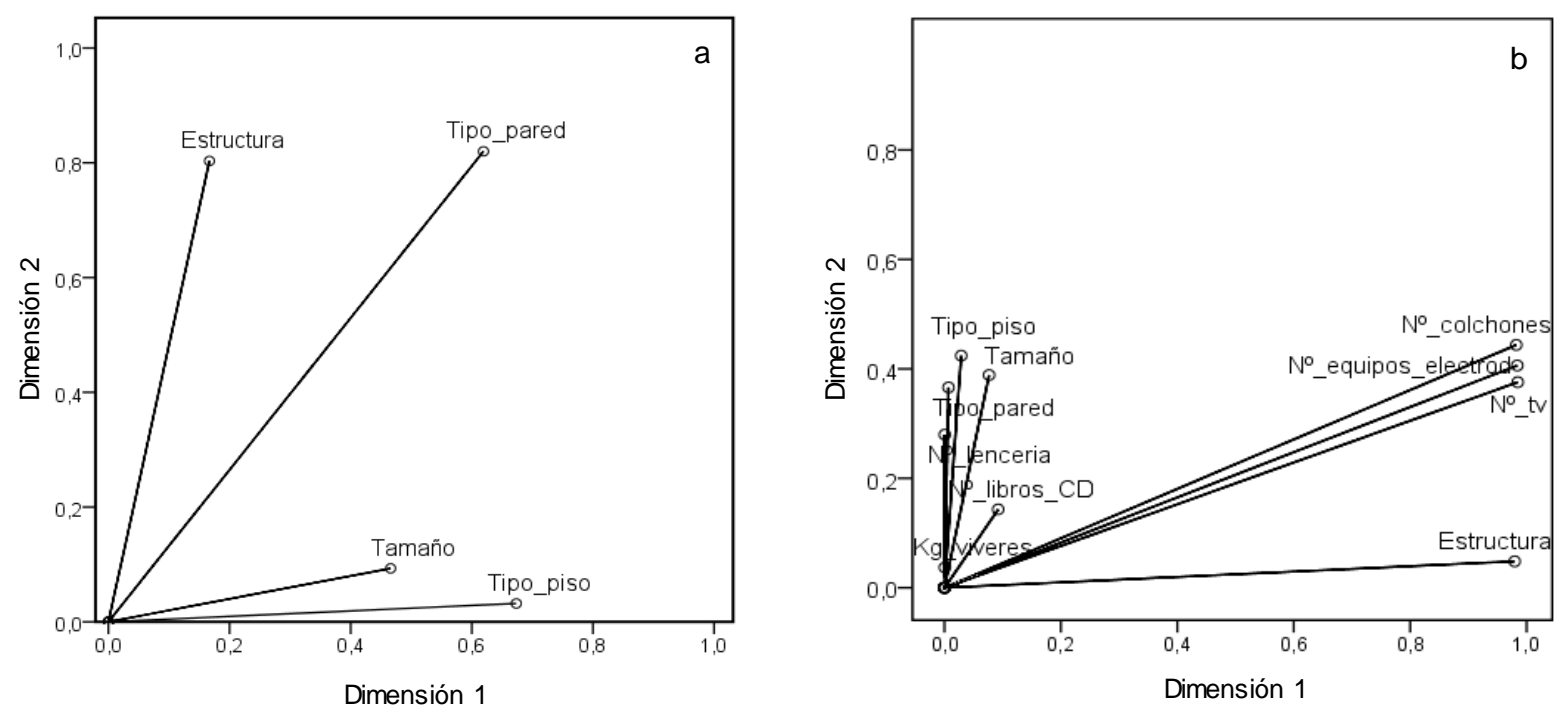

Fig. 3. Mapa del ACM donde se representa la importancia de las variables en cada dimensión para ACM3 (a) y ACM4 (b). 
La cercanía de una variable a un eje es proporcional al grado de asociación con esa dimensión y su longitud se relaciona con la importancia o aporte (medida de discriminación).

En la Tabla 4 se presenta la cantidad de tipologías y viviendas asociadas en los 4 ACM. El ACM1 al no tener todas las variables recodificadas a ordinales (como es el caso de los desniveles) se obtuvo tipologías de viviendas que no conservan las mismas características entre sí, lo que demostró que el ACM no es funcional bajo estas condiciones. Si bien existen asociaciones de viviendas que conservan algunas variables 0 características comunes, esto genera diferencia en la vulnerabilidad; por ejemplo, una vivienda que se diferencia de otra solo por la pared de bahareque tiene efectos distintos a la hora de ser expuesta a inundación en comparación a otra con pared de bloque. Este aspecto mejoró en el resto de los análisis que utilizan solamente variables categóricas tal como debe ser en un ACM (D'Esposito et al., 2014; Esmaelian et al., 2017) obteniendo en efecto tipologías de viviendas con características semejantes u homogéneas. El ACM1 mostró una aparente asociación de viviendas en 5 tipologías, sin embargo, al revisar sus características se encontró profundas diferencias entre los grupos, lo que también se corroboró al realizar un zoom a los datos, este es un problema grafico debido al hecho de tener casos muy numerosos que, gráficamente, pueden aparecer como un solo grupo (incluso muchos puntos se superponen), de ahí la importancia de ampliar y revisar con precaución. Para el ACM2, ACM3 y ACM4 las asociaciones fueron bien definidas y el zoom solo se hizo para apreciar mejor los grupos.

Tabla 4: Tipologías y viviendas agrupadas en los análisis de correspondencias múltiples (ACM).

\begin{tabular}{|c|c|c|c|c|c|}
\hline ACM & $\begin{array}{c}N^{\circ} \text { de } \\
\text { tipologías }\end{array}$ & $\begin{array}{c}N^{\circ} \text { de } \\
\text { viviendas } \\
\text { agrupadas }\end{array}$ & $\begin{array}{c}\% \text { de } \\
\text { viviendas } \\
\text { agrupadas }\end{array}$ & $\begin{array}{c}\text { Homogeneidad de las } \\
\text { características dentro cada } \\
\text { tipología a }\end{array}$ & $\begin{array}{c}\text { Identificación } \\
\text { de viviendas } \\
\text { vulnerables }\end{array}$ \\
\hline 1 & 5 & 411 & 100,00 & $\mathrm{No}$ & $\mathrm{Si}$ \\
\hline 2 & 20 & 329 & 81,03 & $\mathrm{Si}$ & $\mathrm{Si}$ \\
\hline 3 & 13 & 359 & 88,42 & $\mathrm{Si}$ & $\mathrm{Si}$ \\
\hline 4 & 15 & 92 & 29,11 & $\mathrm{Si}$ & $\mathrm{Si}$ \\
\hline
\end{tabular}

En la Figura 4a se muestra el resultado del ACM3, en el que se pudo determinar 13 tipologías, fue necesario realizar un zoom para disgregar los puntos que a simple vista estaban superpuestos para determinar el número y características de viviendas asociadas en cada grupo (Figura 4b). No obstante, quedaron algunas viviendas que no compartieron afinidad, el caso identificado con el número 69 el de la vivienda más alejada por sus características de muy grande, paredes de lata/plástico, piso de cemento entre otras, como también al opuesto la vivienda 127, pequeña con paredes de lata/plástico.
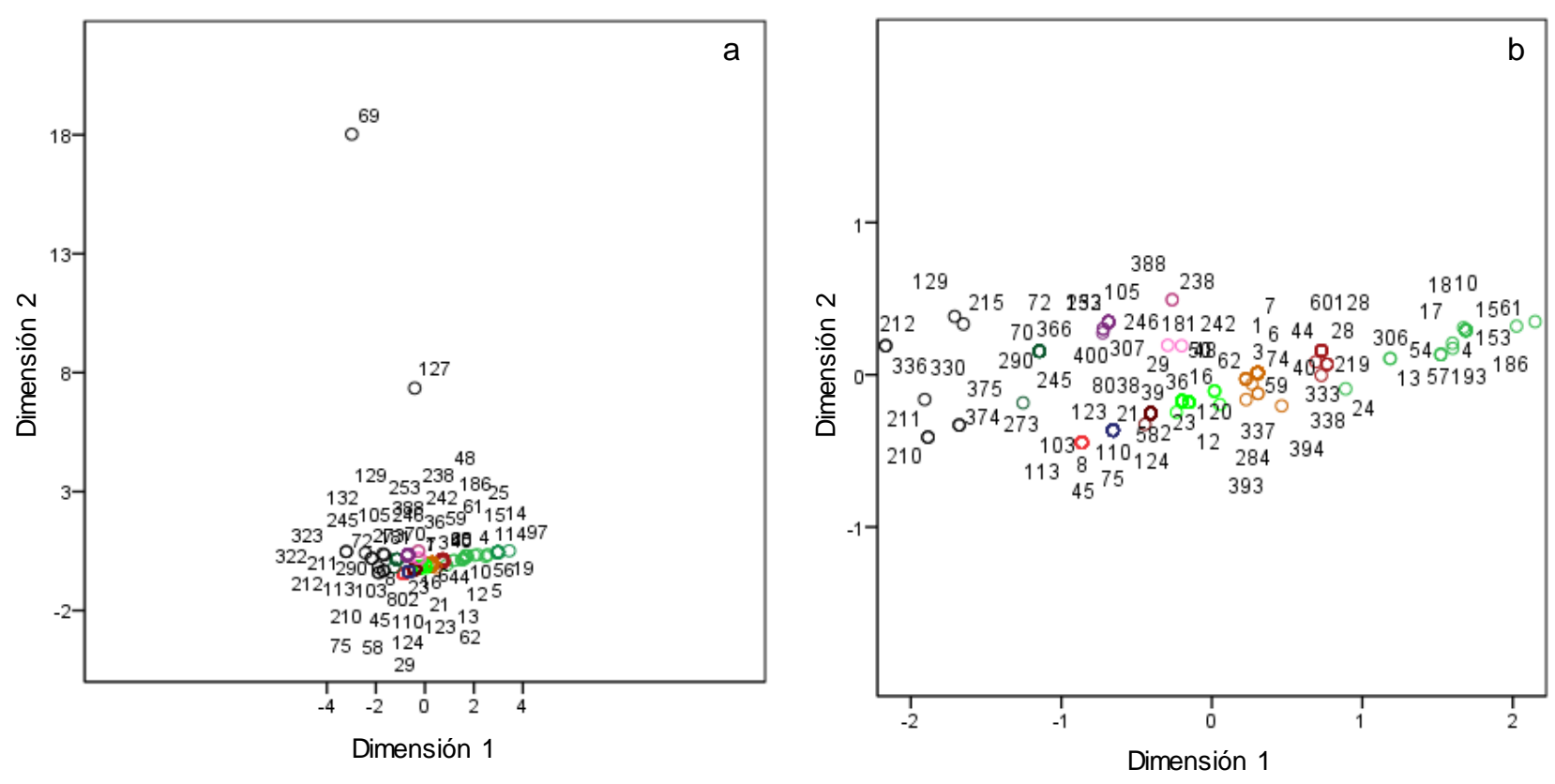

Fig. 4: Asociaciones del Análisis de correspondencia múltiple. Mapa ACM3 (a) y zoom ACM3 (b). 
En la Tabla 5 se presenta el número de viviendas de las 13 tipologías identificadas en el ACM3 -las cuales representan el $88,42 \%$ de los 406 casos considerados en ese análisis. Al observar las características de las viviendas se nota homogeneidad en cada tipología. De acuerdo a los criterios de selección y los resultados mostrados en la Tabla 3 y 4, el ACM3 es el más adecuado. De las 13 tipologías, la IV, V, IX fueron las que agruparon el mayor número de viviendas, representando el 59,05\% de las viviendas agrupadas (359 viviendas); así como también agruparon el mayor número de personas y bienes de acuerdo a los datos reportados en la encuesta. En estas tipologías se encontró un total de 2034 personas (1.105 adultos y 929 niños), y un total de bienes de 256.190 entre colchones, televisores, electrodomésticos, lencería, libros, CD y víveres.

Tabla 5: Número de viviendas por tipologías y sus características estructurales agrupadas en el ACM3.

\begin{tabular}{ccccccc}
\hline Tipología & Tamaño & Estructura & Tipo Paredes & Tipo Pisos & $\begin{array}{c}N^{\circ} \text { de } \\
\text { viviendas }\end{array}$ & \% del total \\
\hline I & Pequeña & 1p_con_patio & Bahareque o barro & Tierra/arena & 15 & 4,18 \\
II & Pequeña & 1p_con_patio & Bahareque o barro & Cemento & 13 & 3,62 \\
III & Pequeña & 1p_con_patio & Ladrillo & Cemento & 17 & 4,73 \\
IV & Pequeña & 1p_con_patio & Bloque & Cemento & 85 & 23,68 \\
V & Mediana & 1p_con_patio & Bloque & Cemento & 69 & 19,22 \\
VI & Pequeña & 1p_con_patio & Bloque & Baldosa/vinilo & 22 & 6,13 \\
VII & Grande & 1p_con_patio & Bloque & Cemento & 32 & 8,91 \\
VIII & Mediana & 1p_con_patio & Bloque & Baldosa/vinilo & 29 & 8,08 \\
IX & Grande & 1p_con_patio & Bloque & Baldosa/vinilo & 40 & 11,14 \\
X & Muy grande & 1p_con_patio & Bloque & Baldosa/vinilo & 15 & 4,18 \\
XI & Muy grande & 1p_con_patio & Bloque & Cemento & 13 & 3,62 \\
XII & Mediana & 1p_con_patio & Ladrillo & Cemento & 5 & 1,39 \\
XIII & Pequeña & 1p_sin_patio & Bloque & Cemento & 4 & 1,11 \\
\hline
\end{tabular}

Las tipologías de viviendas encontradas están directamente relacionadas con el nivel socioeconómico de Riohacha y en especial de los habitantes de la zona, lo que corrobora lo expresados por varios investigadores, es decir los recursos económicos disponibles definen las clases sociales (Suriya et al., 2012; Van Ootegem et al., 2015; Win et al., 2018) y los factores que determinan el tipo de construcción (Lang et al., 2018). De acuerdo a los resultados de la encuesta, los residentes en las tipologías II, IV y V devengan en promedio ingresos menores a un salario mínimo legal al año 2013 y en todos los casos los ingresos son inferiores 1,45 salarios mínimos. El $68,40 \%$ de las viviendas encuestadas pertenecen al estrato 1 , el $27,01 \%$ al estrato 2 y el $4,59 \%$ restante distribuido entre estrato 0 y 3 . En Colombia existe una heterogeneidad en el tipo de viviendas que los usuarios adquieren en relación a su capacidad económica. Las características específicas del bien inmueble, su dotación de servicios y localización en el espacio urbano dependen esencialmente de la capacidad de pago de la familia.

Los ingresos y nivel social son usados para definir las tipologías de viviendas de forma directa e indirecta, es así como en el Estado de México, municipio de Toluca Baró-Suárez et al. (2007) utilizaron la información oficial que considera la estructura básica de acuerdo al nivel socioeconómico; sin embargo, esta clasificación no presenta el tipo de estructura, tipo de material, tamaño entre otros. De forma semejante en la ciudad de Itajubá (Brasil) se caracterizaron las construcciones en categorías de acuerdo al nivel socioeconómico considerado como: alto, normal, bajo y clase trabajadora (Nascimento et al., 2007). En países como Italia Luino et al. (2009) han considerado el tipo de estructura y su valor definidos en la base de datos inmobiliarios, valores que se actualizan cada 6 meses. También se ha definido una tipología sintética de vivienda común de $80 \mathrm{~m}^{2}$ y sus posibles bienes (Velasco et al., 2015), en el norte de Bélgica se usan tipologías de la literatura existente considerando categorías como: viviendas unifamiliares (adosada), unifamiliar (semi-adosada) y de dos plantas o edificios (Van Ootegem et al., 2015).

De forma semejante a esta investigación, Win et al., (2018) definieron las tipologías de las construcciones tomando los resultados de la encuesta aplicada a su área de estudio, encontrando que en el área residencial las viviendas se categorizaron en grupos de acuerdo al material de la estructura como: casas de ladrillo, casas de madera y cabañas de bambú; de acuerdo a la altura de zócalo clasificadas en: de una planta, de dos pisos y de zancos (pilotes). Estos investigadores usaron modelos de regresión para determinar las curvas de daños donde cada uno de los atributos descriptores (entre ellos el tipo de material de la construcción) jugaba el rol 
de factor de vulnerabilidad a la amenaza, y se disponía de datos de daños sufridos, es decir la tipología era "capturada" por el modelo. También en nuestro caso intentamos hacerlo utilizando la información de los daños registrados, pero con resultados poco satisfactorios, principalmente porque muchos residentes no arreglaron sus casas ni repusieron todos los bienes perdidos. En cambio, para explorar una vía alternativa, más directa, para construir las curvas de daños, se decidió justamente identificar por separado las tipologías y luego construir pocas curvas con un enfoque ingenieril para cada tipología.

\section{Ubicación de los elementos expuestos en la zona inundada}

Para observar la ubicación de las tipologías (ACM3) respecto a las zonas inundadas, las viviendas correspondientes fueron ubicadas en un mapa de inundación resultado de la simulación del evento de referencia (18 de septiembre del 2011), tal como se observa en la Figura 5, el tamaño del punto es proporcional al número de viviendas de cada tipología. Esta simulación fue realizada usando el modelo hidráulico bidimensional IBER (Pérez et al., 2016). Se recuerda solo aquí que IBER hace parte de una familia de modelos matemáticos 2D para la simulación del flujo en lámina libre; el modelo se basa en un esquema numérico de volumen finito que resuelve ecuaciones de aguas someras en dos dimensiones (Bladé et al., 2014); para el caso de inundación la entrada es la precipitación y la base para el cálculo es la topografía; IBER permite obtener la profundidad de la inundación en cualquier punto de interés, lo que identifica las áreas inundadas.

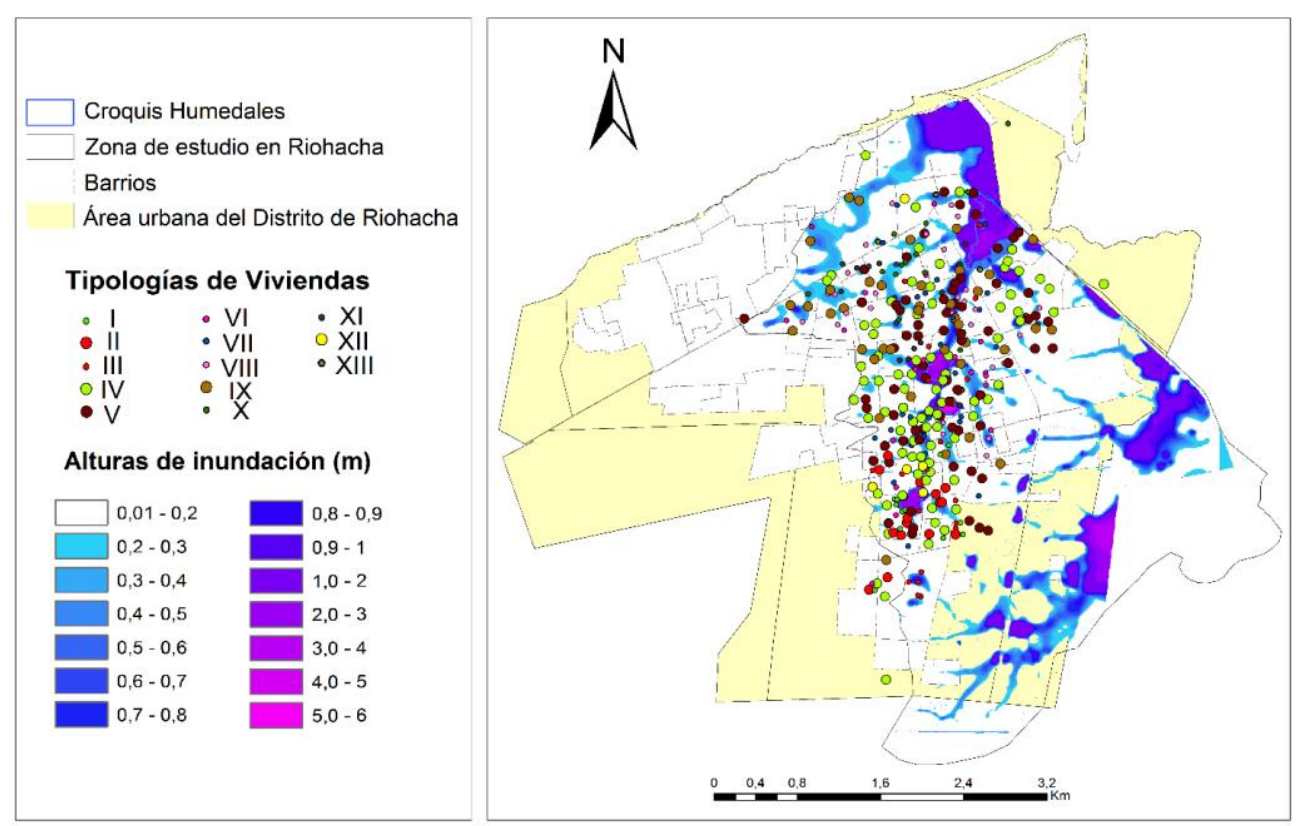

Fig. 5: Mapa de inundación del evento de septiembre de 2011 con ubicación de las tipologías de viviendas en la zona de estudio.

Las viviendas consideradas se distribuyen desde el norte hasta el sur oeste de la ciudad ocupando toda la franja de los humedales, la mayor parte de ellas está en el área de influencia directa de estos cuerpos de agua. De las 359 viviendas representadas en el ACM3, 135 están ubicadas directamente sobre la zona inundada, y durante el evento considerado resultaron afectadas con nivel del agua $\geq 0,2 \mathrm{~m}$. La tipología IV fue la que obtuvo el mayor número de viviendas inundadas y las tipologías XII y la XIII los menores casos, lo cual es proporcional al total de viviendas de cada tipología.

\section{Tipologías de vivienda seleccionadas}

El análisis permitió finalmente concluir con cinco tipologías, tres que presentaron los mayores porcentajes (\%) de viviendas agrupadas y dos que, si bien tuvieron los menores \%, tenían una característica estructural diferente a las anteriores y propias de las viviendas más vulnerables como es el caso de la tipología II que tiene pared de bahareque o barro y la XII con pared ladrillo desnudo (ver Tabla 6); por tanto fueron incluidas para determinar las curvas de daños. En efecto, en las viviendas con pared de bahareque el barro es disuelto fácilmente en el agua, por tanto, son muy vulnerables cuando se expone a inundación incluso por periodos corto de tiempo. Los materiales de construcción y acabados juegan un papel importante, la falta de recubrimiento en la pared o baldosa vinilo en los pisos facilita la penetración del agua a la construcción aumentando el daño por deterioro. 
Las tipologías seleccionadas fueron por tanto bien diferenciadas y representativas de la realidad presente dado que capturan globalmente el 59,05\% de los casos agrupados en el ACM. Estas viviendas experimentan una fuerte amenaza dada la alta probabilidad de inundación, al tiempo que son construcciones muy vulnerables, lo que indica que hay un gran número de habitantes y bienes en riesgo. Las tipologías no consideradas tenían pocos casos, eran similares o menos vulnerables que las seleccionadas, por tanto, no afectan los resultados. Un número pequeño de tipologías es deseable, Trubka y Glackin (2016) definieron 4 tipologías residenciales para un barrio típico en el Estado la Victoria, Australia, todas para viviendas unifamiliares así: 1 planta y 2 habitaciones, 1 planta y 3 habitaciones, 1 Planta y 4 habitaciones, 2 Plantas y 4 habitaciones; pero en este caso solo estaban relacionadas con el tamaño y tipo de estructura.

Tabla 6: Tipologías de viviendas a utilizar para construir las curvas de daños por los dos enfoques.

\begin{tabular}{ccccccc}
\hline Tipología & Tamaño & Estructura & Tipo de Paredes & Tipo de Piso & $\begin{array}{c}\text { Número de } \\
\text { Viviendas }\end{array}$ & $\begin{array}{c}\text { Porcentaje } \\
\text { del Total }\end{array}$ \\
\hline IV & Pequeña & 1 piso con patio & Bloque & Cemento & 85 & 23.67 \\
V & Mediana & 1piso con patio & Bloque & Cemento & 69 & 19.22 \\
IX & Grande & 1piso con patio & Bloque & Baldosa/vinilo & 40 & 11.14 \\
II & Pequeña & 1piso con patio & Bahareque o barro & Cemento & 13 & 3.62 \\
XII & Mediana & 1piso con patio & Ladrillo & Cemento & 5 & 1.40 \\
\hline
\end{tabular}

En la Figura 6 se muestra las imágenes típicas de las tipologías IV (área construida $64 \mathrm{~m}^{2}$, de 1 piso con patio en suelo desnudo, pared de bloque desnudo, piso en cemento, y un solo cuarto), tipología $V$ (área construida $120 \mathrm{~m}^{2}$, de 1 piso con patio en suelo desnudo, pared de bloque desnudo, piso de cemento y dos cuartos) y la tipología II (área construida $64,70 \mathrm{~m}^{2}$, de 1 piso con patio en suelo desnudo, pared de bahareque, piso de cemento y un cuarto). Como se puede observar por sus condiciones y características son viviendas muy vulnerables a eventos de inundación.
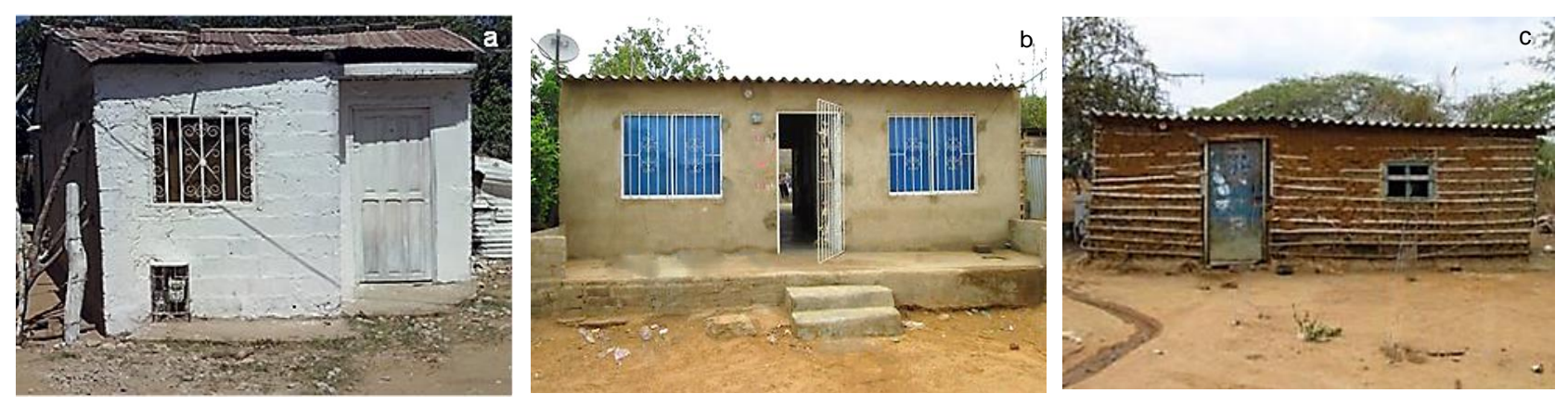

Fig. 6: Imágenes de tipologías representativas en las zonas inundadas. Tipología IV (a), tipología V (b) y tipología II (c) (Fuente: equipo de trabajo del proyecto MODCEL)

Tal como se expresó en el apartado "Estado de las viviendas al momento de aplicar la encuesta", los factores que influyen en la determinación o cambio de una tipología de vivienda aún se conservan en Riohacha, a pesar de ver los efectos, se sigue haciendo las mismas construcciones y lo que es peor; se ocupan espacios de alto riesgo de inundación. Las instituciones gubernamentales actúan de forma reactiva y no proactiva como debe ser. En el mes de agosto de 2016 se asignaron 55 nuevas viviendas de interés social fuera de la zona de estudio (Lomas de Trupío) y hasta la fecha (casi dos años después) están deshabitadas por problemas de inundación, cuya solución planteada ahora es la construcción de una estación de bombeo para las aguas pluviales. La presencia de indígenas Wayuu además agrega otra dimensión, tanto por el nivel de pobreza en que muchos de ellos viven, como por el factor cultural, por lo que su vivienda típica es de bahareque. En general, los constructores o albañiles no se han capacitado para diseñar viviendas adaptadas a problemas de inundación. Cabe recordar que a pesar de Riohacha sufrir por inundaciones frecuentes, las registradas en el 2010-2011 son las más fuertes de los últimos 50 años (Hoyos et al., 2013), y por tanto, casi la totalidad de sus habitantes no habían experimentado una inundación de tal magnitud. Se espera que este hecho marcara un cambio de actitud, aunque 6 años después de ocurrido el evento no ha sido notorio.

De acuerdo a lo anterior, y dado que las viviendas no han sido reconstruidas con criterios de adaptación, mientras numerosas nuevas viviendas han aparecido en la zona, si se diera una nueva inundación similar a 
la registrada en el periodo 2010-2011, las consecuencias serían seguramente mucho peor. En efecto, Riohacha ha experimentado en los últimos años un crecimiento urbanístico acelerado, incluso en zonas de alto riesgo de inundación, lo que incrementa notablemente el valor expuesto y además reduce la capacidad de infiltración y por tanto mayor inundación con lluvia de la misma intensidad. Los resultados de este trabajo junto con el plan de solución elaborado en el proyecto MODCEL fueron presentados y socializados en varios eventos donde las autoridades competentes especialmente el ente territorial estaban presentes. Sin embargo, la implementación de estas medidas es un tema que aún no se concreta, siendo la mayor dificultad la falta de planificación y la inestabilidad del jefe del Distrito, pues en los dos últimos años han pasado por el Distrito cuatro Alcaldes.

\section{CONCLUSIONES}

A partir de los resultados obtenidos, se pueden extraer las siguientes conclusiones:

1.- En este artículo se muestra como a través del Análisis de Correspondencias Múltiples, se puedo determinar tipologías de vivienda como un paso fundamental previo a la estimación cuantitativa de los daños directos tangibles a través de curvas de daños. La metodología adoptada resultó ser adecuada por su versatilidad y fácil de utilizar a pesar que requiere realizar un zoom al mapa perceptual cuando el análisis se hace con numerosos casos.

2.- Las viviendas expuestas en el área de estudio, se pudieron agrupar en 13 tipologías, de las cuales cinco de ellas logran ser suficientemente representativas de la realidad presente, dado que capturan globalmente el $59,05 \%$ de los casos agrupados y el $52,21 \%$ del total de los casos del ACM3. Las tipologías no seleccionadas tenían menor número de viviendas o guardaban cierta similitud a las ya consideradas. Estas tipologías están acorde a las condiciones socioeconómicas y culturales de la zona y demás factores que definen el tipo de vivienda.

3.- Las viviendas encontradas son muy vulnerables, en su mayoría construcciones pequeñas, solo el $26,1 \%$ de las viviendas encuestadas tienen piso de baldosa/vinilo. Las construcciones más vulnerables tienen pared de bahareque, dado que este material es disuelto cuando se expone al agua e incluso por tiempos cortos. Lo anterior hace necesario implementar el plan de soluciones determinadas en el proyecto MODCEL, como por ejemplo reconstruir las viviendas en pilotes, y/o usar materiales de construcción acordes a los requerimientos del entorno.

4.- Durante el evento de inundación del 18 de septiembre del 2011 resultaron afectadas 135 viviendas donde la cercanía con los humedales tuvo influencia bien marcada por las mayores profundidades alcanzadas en esos lugares. Esto implica acciones urgentes de planificación del territorio por parte del Distrito de Riohacha.

5.- Las tipologías determinadas son representativas del área estudiada y son significativas en cuanto en igualdad de calado los daños pueden variar sustancialmente de acuerdo a la tipología de vivienda, lo que se agrava porque muchas de ellas se encuentran en zonas de alto riesgo de inundación.

\section{AGRADECIMIENTOS}

Se agradece a la Unidad Nacional para la Gestión de Riesgos de Desastres (UNGRD) de Colombia por la financiación del proyecto MODCEL, a la Universidad de La Guajira por financiar esta investigación y a nivel internacional a la Universidad Federal de Rio de Janeiro de Brasil, COPPETEC/PEUPOLI. Al equipo de trabajo del proyecto MODCEL, por la información básica de las encuestas.

\section{REFERENCIAS}

Banco Interamericano de Desarrollo (BID), Valoración De Daños y Pérdidas. Ola Invernal en Colombia 2010-2011", Comisión Económica para América Latina y el Caribe (CEPAL), Bogotá, Colombia (2012)

Banco Mundial, Proyecto CAPRA (Probabilistic Risk Assessment Program). Notas Técnicas Métodos de Evaluación de Riesgos y amenazas de Inundación, Washington D.C, EE.UU. (2016)

Baró-suárez, J.E., C. Díaz-Delgado y M.V. Esteller-Alberich, Curvas de Daños Económicos Provocados por Inundaciones en Zonas Habitacionales y Agrícolas de México. Parte I: Propuesta Metodológica, Ingeniería Hidráulica en México, XXII (1), 91-102 (2007)

Bladé, E., L. Cea y otros seis autores, lber: Herramienta de Simulación Numérica del Flujo en Ríos", doi: http://doi.org/10.1016/j.rimni.2012.07.004, Rev. Int. Metod. Numér, 30(1), 1-10 (2014)

Budiyantini, Y. y V. Pratiwi, Peri-urban Typology of Bandung Metropolitan Area, Procedia - Social and Behavioral Sciences, doi: http://doi.org/10.1016/j.sbspro.2016.06.152, CITIES 2015 International Conference, Intelligent Planning Towards Smart Cities, CITIES 2015, 3-4 November 2015, Surabaya, Indonesia, 227, 833-837 (2016) 
Chatterjee, A., A. Ghosh y B.K. Chakrabarti, Socio-economic inequality: Relationship between Gini and Kolkata Indices, doi: http://doi.org/10.1016/j.physa.2016.09.027, Physica A: Statistical Mechanics and Its Applications, 466, 583-595 (2017)

CREACUA- Centro de Recuperación de Ecosistemas Acuáticos, Informe del Proyecto: "Adaptación Urbana Verde frente a inundaciones con el soporte de la modelación matemática y del software MODCEL en Riohacha, La Guajira, Colombia", Convenio de Cooperación № 9677-04-1047-2013, CREACUA, Riohacha, La Guajira-Colombia (2015)

DANE- Departamento Nacional de Estadísticas, Indicadores de Pobreza, Colombia, Bogotá-Colombia (2018)

D'Esposito, M.R., D. De Stefano y R. Ragozini, On the use of Multiple Correspondence Analysis to Visually Explore Affiliation Networks, doi: http://doi.org/10.1016/j.socnet.2014.01.003, Social Networks, 38(1), 28-40 (2014)

Esmaelian, M., M. Tavana, D. Di Caprio y R. Ansari, A Multiple Correspondence Analysis Model for Evaluating Technology Foresight Methods, doi: http://doi.org/10.1016/J.TECHFORE.2017.07.022, Technological Forecasting and Social Change, 125, 188-205 (2017)

Fithian, W. y J. Josse, Multiple Correspondence Analysis and the Multilogit Bilinear Model, doi: http://doi.org/10.1016/j.jmva.2017.02.009, Journal of Multivariate Analysis, 157, 87-102 (2017)

Hermosilla, T., J. Palomar-Vázquez y otros tres autores, Using street Based Metrics to Cracterize Urban Typologies, Computers, doi: http://doi.org/10.1016/j.compenvurbsys.2013.12.002, Environment and Urban Systems, 44, 68-79 (2014)

Hoyos, N., J. Escobar y otros tres autores, Ortiz, J.C., Impact of the 2010-2011, La Niña Phenomenon in Colombia, South America: the Human toll of an Extreme Weather Event, doi: http://dx.doi.org/10.1016/j.apgeog.2012.11.018, Applied Geography, 39, 16-25 (2013)

IPCC, Summary for Policymakers. In: Managing the Risks of Extreme Events and Disasters to Advance Climate Change Adaptation [Field, C.B., V. Barros, T.F. Stocker, D. Qin, D.J. Dokken, K.L. Ebi, M.D. Mastrandrea, K.J. Mach, G.K. Plattner, S.K. Allen, M. Tignor, and P.M. Midgley (Eds.)]. A Special Report of Working Groups I and II of the Intergovernmental Panel on Climate Change, Cambridge University Press Cambridge, U.K. and New York, NY, USA, 1-19 (2012)

Kundzewicz, Z.W., S. Kanae otros 15 autores, Flood Risk and Climate Change: Global and Regional Perspectives, doi: http://dx.doi.org/10.1080/02626667.2013.857411, Hydrological Sciences Journal, 59(1), 1-28 (2013)

Lang, D.H., A. Kumar, S. Sulaymanov y A. Meslem, Building Typology Classification and Earthquake Vulnerability Scale of Central and South Asian Building Stock, doi: http://doi.org/10.1016/j.jobe.2017.11.022, Journal of Building Engineering 15, 261-277 (2018)

Loga, T., B. Stein y N. Diefenbach, TABULA Building Typologies in 20 European Countries-Making Energy-Related Features of Residential Building Stocks Comparable, doi: http://doi.org/10.1016/j.enbuild.2016.06.094, Energy and Buildings, 132, 4-12 (2016)

Luino, F., C.G. Cirio y otros cinco autores, Application of a Model to the Evaluation of Flood Damage, doi: http://doi.org/10.1007/s10707-008-0070-3, Geolnformatica, 13(3), 339-353 (2009)

Mahayuddin, S.A., W.A.Z.W. Zaharuddin, S.N. Harun y B. Ismail, Assessment of Building Typology and Construction Method of Traditional Longhouse, doi: http://doi.org/10.1016/j.proeng.2017.04.261, Procedia Engineering, 180, 1015-1023 (2017)

Merz, B., H. Kreibich, R. Schwarze y A. Thieken, Review Article "Assessment of Economic Flood Damage", doi: http://doi.org/10.5194/nhess-10-1697-2010, Natural Hazards and Earth System Science, 10(8), 1697-1724 (2010)

Municipio de Riohacha, Concejo Municipal para la Gestión del Riesgo de Desastres, Plan municipal de Gestión de Riesgo de Desastres (2012)

Nascimento, N., L.M. Machado, M. Baptista y A. De Paula, The Assessment of Damage Caused by Floods in the Brazilian Context, doi: http://doi.org/10.1080/15730620701466591, Urban Water Journal, 4(3), 195-210 (2007)

Nardini, A. y M.G. Miguez, An Integrated Plan to Sustainably Enable the City of Riohacha (Colombia) to Cope With Increasing Urban Flooding, While Improving its Environmental Setting, doi: http://doi.org/10.3390/su8030198, Sustainability (Switzerland), 8(3), 1-29 (2016)

Padilla, C.M., W. Kihal-Talantikit, S. Perez y S. Deguen, Use of Geographic Indicators of Healthcare, Environment and Socioeconomic Factors to Characterize Environmental Health Disparities, doi: http://doi.org/10.1186/s12940-016-0163-7, Environmental Health, 15(1), 79 (2016)

Palacio, L., Inundaciones en Colombia: El Peor Invierno en 55 años, Revista Fasecolda, (141), 13-16 (2011)

Pérez, J.I., A.G. Nardini, Y.A. Movil y L. Cárdenas, Análisis Comparativo de la Modelación de Inundaciones Obtenidas con los Software MODCEL e IBER en Riohacha, La Guajira - Colombia, Informe Proyecto Investigación, Facultad de Ingeniería, Universidad de La Guajira, Colombia (2016)

Rodrigues, L., R. Grave, J.M. de Oliveira y C. Nogueira, Estudio sobre Bullying Homofóbico en Portugal con Recurso al Análisis de Correspondencias Múltiples (ACM), doi: http://doi.org/10.1016/j.rlp.2016.04.001, Revista Latinoamericana de Psicologia, 48(3), 191-200 (2016)

Sedano, K., Y. Carvajal y A. Ávila, Análisis de Aspectos que Incrementan el Riesgo de Inundaciones en Colombia, doi: http://doi.org/10.17151/luaz.2013.37.13, Luna Azul, (37), 219-238 (2013)

Sowmya, K.., C.M. John y N.K. Shrivasthava, Urban Flood Vulnerability Zoning of Cochin City, Southwest Coast of India, Using Remote Sensing and GIS, doi: http://doi.org/10.1007/s11069-014-1372-4, Natural Hazards, 75(2), 1271-1286 (2015) 
Suriya, S., B.V. Mudgal y P. Nelliyat, Flood Damage Assessment of an Urban Area in Chennai, India, Part I: Methodology, doi: http://doi.org/10.1007/s11069-011-9985-3, Natural Hazards, 62(2), 149-167 (2012)

Trubka, R. y S. Glackin, Modelling Housing Typologies for Urban Redevelopment Scenario Planning, doi: http://doi.org/10.1016/j.compenvurbsys.2015.11.002, Computers, Environment and Urban Systems, 57, 199-211 (2016)

Valdivieso, C., R. Valdivieso y O. Valdivieso, Determinación del Tamaño Muestral Mediante el Uso de Árboles de Decisión, UPB, Investigación \& Desarrollo, 11, 148-176 (2011)

Van Ootegem, L., E. Verhofstadt, K. Van Herck y T. Creten, Multivariate Pluvial Flood Damage Models, doi: http://doi.org/10.1016/j.eiar.2015.05.005, Environmental Impact Assessment Review, 54, 91-100 (2015)

Velasco, M., À. Cabello y B. Russo, Flood damage assessment in urban areas, Application to the Raval district of Barcelona using synthetic depth damage curves, doi: http://doi.org/10.1080/1573062X.2014.994005, Urban Water Journal, 13(4), 426-440 (2015)

Vojinovic, Z. y D. Tutulic, On the use of 1D and Coupled 1D-2D Modelling Approaches for Assessment of Flood Damage in Urban Areas, doi: http://doi.org/10.1080/15730620802566877, Urban Water Journal, 6 (3), 183-199 (2009)

Vujicic, T., Urban and Architectural Typology of Industrial Structures Versus their Photographic Typology - A Comparitive Analysis, PhIDAC, 1-8 (2011)

Win, S., W.W. Zin, A. Kawasaki y Z.M.L.T San, Establishment of Flood Damage Function Models: A Case Study in the Bago River Basin, Myanmar, doi: http://doi.org/10.1016/j.ijdrr.2018.01.030, International Journal of Disaster Risk Reduction, in press (2018)

Young, R., J. Zanders, K. Lieberknecht y E.A. Fassman-Beck, Comprehensive Typology for Mainstreaming Urban Green Infrastructure, doi: http://doi.org/10.1016/j.jhydrol.2014.05.048, Journal of Hydrology, 519(PC), 2571-2583 (2014) 
